\title{
The influence of the external costs of modal split in the transport network, with particular reference to rail transport
}

\author{
T. Ambroziak ${ }^{1}$, P. Gołębiowski ${ }^{1}$, I. Jacyna-Gołda ${ }^{2}$, \\ R. Jachimowski ${ }^{1}$, A. Merkisz-Guranowska ${ }^{3}$, J. Pielecha ${ }^{3}$, \\ D. Pyza ${ }^{1}$, E. Szczepański ${ }^{1}$, M. Wasiak ${ }^{1} \&$ J. Żak ${ }^{1}$ \\ ${ }^{I}$ Faculty of Transport, Warsaw University of Technology, Poland \\ ${ }^{2}$ Faculty of Production Engineering, \\ Warsaw University of Technology, Poland \\ ${ }^{3}$ Faculty of Machines and Transport, \\ Poznan University of Technology, Poland
}

\begin{abstract}
Vehicles have an impact on environmental pollution through emissions. Thus, they generate different carbon footprints, or emit different amounts of carbon dioxide into the atmosphere. This article attempts to determine the effects of carbon dioxide on the distribution of the traffic stream in the selected part of the transport network. For the analysis the Warsaw-Krakow route was chosen. The movement between these two cities can be performed with different modes of transport. The distribution of the passenger streams was conducted for three variants of the three sub-criteria: minimum average costs, minimum marginal costs and the costs of environmental pollution. The unitary cost of carbon dioxide emission was determined using a $\mathrm{CO}_{2}$ Calculator. The selection of the variant of the passenger stream distribution was carried out using a multi-criteria evaluation method called MAJA.
\end{abstract}

Keywords: traffic stream distribution, carbon dioxide, multi-criteria evaluation.

\section{Introduction}

Development of transport system in Poland comes from the forecasts of transportation needs and from forecast of the system infrastructure adaptation to the standards and requirements of the European Union. International cooperation 
requires the creation of a transport network which meets the needs of the growing transport task. Hence, the development of the transport system should rely on determining the relationship between the predicted size of the tasks included in the system and the cost of implementing these tasks. However, modernization and development cannot rely only on the creation of an integrated transport network and increased bandwidth - although this is very important - but it must go hand in hand with the improvement of safety and environmental protection [5].

The significant impact on the environment has a degree of emissions generated by transport. One of the substances produced by the means of transport is carbon dioxide. Its amount, depending on the emission using different vehicles is then called "the climate trace". $\mathrm{CO}_{2}$ emissions per capita in Poland is at the level of the average for the European Union countries [4].

This article attempts to assess the impact of carbon dioxide emissions on the distribution of the passenger stream in a selected part of the transport network. The issue of carbon dioxide emissions and the study of its amount in the literature is analyzed by many researchers [11-13]. Problems include modeling of carbon dioxide emission for different cases, and the software used for this modeling e.g. COPERT II.

For the studies referring to the distribution of the passenger and cargo stream on the road and rail network between the communication course of Gdańsk-Katowice, one of the criteria for partial distribution criterion was equal to the external costs [9].

This article attempts to assess the impact of carbon emissions on the distribution of the passenger stream in a selected part of the transport network. For the analysis, the communication route Warsaw-Krakow was chosen. Different modes of transport that emit different amounts of $\mathrm{CO}_{2}$ can be used to move between these two cities. The distribution of the traffic stream was carried out on the basis of three different sub-criteria: minimum average cost, minimum marginal cost and the cost of carbon dioxide emissions. It was performed in three variants: for the current structure of connections with the assumption of the current number of passenger, for the current structure of connections with the assumption of the increasing number of passenger and for the increasing number of passengers and including the high speed railway line development. The multi-criteria evaluation of stream distribution was then performed from the point of view of the above criteria [1].

To calculate the carbon dioxide emissions from various transport modes, the $\mathrm{CO}_{2}$ Calculator was used. This calculator was prepared by Aeris Futuro Foundation for the purpose of the EU Civitas II. One the elements of this program is the Caravel Civitas Project - Cleaner and Better Transport in Cities, which is being implemented since 2006 in Krakow. This calculator allows you to calculate the amount of carbon dioxide produced by one passenger. The basic unit is $1 \mathrm{~kg}$ of $\mathrm{CO}_{2}$ emissions for 1 passenger-kilometer (pkm). On the basis of scientific studies the individual emission values have been prepared [15]. Based on these emission values the computations necessary for the distribution of the traffic stream were performed $[3,17]$. 


\section{Structure of the analyzed transportation network}

The aim of the study of the transport system is to properly identify the processes in it. From the fact that the actual transport system is too complex for the direct analysis, it is necessary to construct its models. The built model of transport system should reflect the complexity and interdependence of the phenomena occurring in the system and its relationship to the environment. Constructing the model of transport system (MST), it is necessary to map the four basic properties of this model: structure, characteristics of the structure elements, traffic stream and the organization understood as a description of using structure elements for the implementation of the transport [6,8].

Thus, the model of transport system (MST) is written as an ordered four: MST $=\langle\boldsymbol{G}, \boldsymbol{F}, \boldsymbol{P}, \boldsymbol{O}>$, for which $\boldsymbol{G}-$ is a graph structure, the $\boldsymbol{F}-$ is a set of functions defined on the nodes, and (or) arcs of the graph structure, $\boldsymbol{P}$ - traffic stream, $\boldsymbol{O}$ - organization. A convenient representation of the structure and characteristics of the transport system is a network which is understood as a network in terms of graph theory $[9,10]$. The network also implies description language of model of the transport system, mathematically rigorous and understood by transport specialists.

So we assume that the network $\boldsymbol{S}$ is understood as an ordered three, what can be written as: $\mathbf{S}=<\mathbf{G}, \boldsymbol{F}_{\boldsymbol{W}}, \boldsymbol{F}_{\boldsymbol{L}}>$, where $\mathbf{G}=<\boldsymbol{W}, \boldsymbol{L}>$ is a graph of the network, where $\boldsymbol{W}$ is the set of transport nodes: $\boldsymbol{W}=\{1, \ldots, i, \ldots, j, \ldots, \mathrm{W}\} ; \boldsymbol{L}-$ is the set of arcs of the graph $\boldsymbol{G}$, i.e. set of elements which are defined as follows:

$$
\boldsymbol{L}=\left\{(i, j): \quad \eta_{i, j}=1, \quad i \neq j, \quad(i, j) \in \boldsymbol{W}\right\}
$$

and have the interpretation of direct transport links (transport sections) between nodes of transport network numbered as $i$ and $j$, where $\eta$ is a projection inflicted on the Cartesian product $\boldsymbol{W} \times \boldsymbol{W}$, which parts of the Cartesian product perform into the set $\{0,1\}$, where $\eta_{i, j}=1$ if there is a direct link between nodes $i$ and $j$ and $(i \neq j)$, otherwise $\eta_{i, j}=0 . \boldsymbol{F}_{\boldsymbol{W}}$ - is a set of functions defined on the vertices of the graph structures, $\boldsymbol{F}_{\boldsymbol{L}}-$ is a set of functions defined on the arcs of the graph structure.

In addition, it is assumed that there is given value of the traffic stream in the given relation $(a, b)$, which is denoted by $x^{a b}$, where $\boldsymbol{A}$ is a set of numbers of the traffic stream sources, $a \in \boldsymbol{A}$ while $\boldsymbol{B}$ is a set of numbers of the traffic stream destinations, $b \in \boldsymbol{B}$. We will now operate with the set of transport relationships $\boldsymbol{E}$ : $\boldsymbol{E} \subset \boldsymbol{A} \times \boldsymbol{B}$ where $(a, b) \in \boldsymbol{E}$.

We assume that for each pair $(a, b) \in \boldsymbol{E}$, there exists a set of roads marked as $\boldsymbol{P}^{\boldsymbol{a} \boldsymbol{b}}$ binding the start and the end of the relation. A single route in a given relation $(a, b)$ will be numbered with the index $p, p \in \boldsymbol{P}^{a b}$. Let $\boldsymbol{X E}$ be the set, with elements defined as follows:

$$
\boldsymbol{X} \boldsymbol{E}=\left\{x(a, b) \equiv x^{a b}:(a, b) \in \boldsymbol{E}\right\}
$$

where $x(a, b) \equiv x^{a b}$ have the interpretation of traffic volume moved in the transport network between a pair of vertices i.e. source of $a$ and the destination $b$. 
We assume that for each relation $(a, b)$, the projection $o$, carrying out the elements of the cartesian product $\boldsymbol{P}^{a b} \times \boldsymbol{X E}$ in the set of real non-negative numbers, where $o\left(p, x^{a b}\right) \in R^{+}$has the interpretation of the organization of the traffic movement on road, $p \in \boldsymbol{P}^{a b}$ in relation $(a, b)$ is defined, which means that we have defined the organization of traffic in the transport network.

The given projection $o$, will define the organization of the tasks in the given transport network. The network structure will be the defined and projected by graph G. The constraints will arise from the sets of functions $\boldsymbol{F}_{\boldsymbol{W}}$ and $\boldsymbol{F}_{\boldsymbol{L}}$, defined respectively on nodes and arcs of the graph structure. Of course:

$$
\boldsymbol{O}=\left\{o: \quad o\left(p, x^{a b}\right) \in R^{+}, \quad p \in \boldsymbol{P}^{a b}, \quad x^{a b} \in \boldsymbol{X} \boldsymbol{E}, \quad(a, b) \in \boldsymbol{E}\right\}
$$

\section{Variants of the traffic stream distribution}

The distribution of the passenger stream on individual connections in the transport network that is a subject of our research will be carried in variants. The set of variants $\boldsymbol{V}$ can be defined as follows (where: v - variant number, $\bar{V}$ - number of variants):

$$
\boldsymbol{V}=\left\{v: v=1,2, \ldots, v^{\prime}, \ldots, \bar{V}\right\}=\{1,2,3\} .
$$

Variant 1 is the distribution of the passenger stream on existing connections in the analyzed part of the transport network. Passenger stream is distributed on rail, air, road and bus connections. The size of the traffic stream, which will be distributed over the network is the same as that for the moment.

Variant 2 is the distribution of the passenger stream on existing connections in the analyzed part of the transport network. Passenger stream is distributed on rail, air, road and bus connections. The size of the traffic stream, which will be distributed over the network will be increased in proportion to the present time by almost $40 \%$.

Variant 3 is the distribution of the passenger stream in the analyzed part of the transport network with the additional connection of High Speed Rail, which construction is expected to begin after the construction of HSR connection "Y" (Warsaw-Lodz-Poznan/Wroclaw with a ramification to the CMK line). The date of finishing this construction is planes for year 2020. The size of the traffic stream, which will be distributed on the network, will be increased in proportion to the present time by almost $40 \%$.

Based on the estimates it was assumed that the stream of passengers incriminating Warsaw-Krakow communications is around 4000 passengers per day $[13,14]$.

Assuming that not all trips are realized every day, the annual stream in the analyzed relation is 1200 thousand of passengers. This size will be distributed on the network in Variant 1. In the Variant 2 and 3 the traffic stream distributed on the network, will be increased in proportion to the present time by almost $40 \%$. 


\section{Criteria for the traffic stream distribution}

The aim of a distribution of the traffic stream on the transport network is to allocate the appropriate size of the stream for the corresponding curves taking into account the restrictions imposed on the network, and in accordance with the indicator of quality solutions - minimizing or maximizing the objective function [2].

The optimizing tasks regarding the distribution of a traffic stream can be single objective as well as multi-criteria. For the study the multi-criteria distribution of a traffic stream in a selected portion of the transport network was carried out.

The analysis takes into account the criterion of minimum average costs, minimum marginal costs and external costs [18].

The average cost criterion used in assessing the distribution of the traffic in multi-modal transport corridor can be considered as an assessment of the cost of transport from the point of view of the transport services buyer. Usually in the system, there are many vehicles drivers forming a traffic stream. Selection of roads in a given relation is made by each traffic participant (decision maker) in accordance with the criterion of maximum benefit, i.e. the minimum loss of movement.

From the equilibrium conditions comes out that, for each relation, the average cost of traffic stream movement of each road relationship is the same, i.e. it is equal to a constant value which is characteristic for the transport network and the size of the demand for transport, while this is the minimum average cost

The distribution of the traffic stream of on the above properties is optimal from the point of view of all the drivers, i.e. presents a situation in which none of the decision makers (drivers) is not able to reduce the costs associated with the carriage or increase its benefits by choosing another route.

The calculation of the marginal cost is used to determine the optimal volume of traffic, i.e. the one for which the total sum of costs takes the smallest value. So, we assume that for the transport system, there is one active element which aim of activity is to use a system equipment, so the total cost of the transport service was minimal. Such action is represented by a single scheduler for the whole system. This means that other users are forced to take a decision in accordance with the decision highlighted the decision-maker. Hence, the result of his action is nothing more than a plan, traffic in the transport network, which described the organization of movement.

From this it follows that for a fixed structure of the system and a set equipment structure elements for optimal allocation of the traffic stream, taking into account the criterion of presenting central to the whole system point of view, it will be distributed with minimal cost realization of the demand for transport. Such an analysis of the distribution of the stream of traffic in the transport network allows it to assess the sustainability of the transport network, i.e. the distribution of traffic on roads used for transport, for which as a result, the marginal cost of each is equal to the minimum and at the same time.

The distribution of traffic stream according to the marginal cost is an estimate of the traffic stream distribution from the perspective of the service provider. Modeling distribution of traffic stream according to this criterion allows primarily 
an assessment of the degree of investment by the providers of transport services, infrastructure, transport network and to identify elements of the transport network invested too much or undercapitalized.

The criterion of external costs allows to analyze the distribution of the traffic stream when the transportation technologies are preferred, for which the harmful impact on the environment is smaller than the other. By the harmful impacts of transport we understand factors such as noise, air pollution, transport accidents or uncovered infrastructure costs that adversely affect the environment. The article analyzes the external costs adjusted for air pollution. Other components of external costs were not included [16].

The degrading impact of transport on the environment pulls together significant costs, both indirect (appear in the design, manufacture, use and destruction of means of transport and infrastructure) and direct (accidents, noise, vibration). Although the effects of this impact are difficult to estimate, these research are conducted more often (such as Poland) [9].

Formally, the criteria for assessment of the organization of a transport system performance $\mathbf{X}(v)$ for each variant $v, v \in \boldsymbol{V}$ has the following form [7]:

- $f_{1}(\mathbf{X}(v))$ - the average cost of movement of the traffic stream on the analyzed part of the transport network (the average cost of movement of the traffic stream on the roads $p$ in relation $(a, b)$ for each variant $v$ are equal and take the minimum value):

$$
f_{1}(\mathbf{X}(v))=\min _{\{\mathbf{X}(v)\}}\left\{c^{p, a b}(\mathbf{X})=c^{p^{\prime}, a b}(\mathbf{X})\right\}
$$

- $f_{2}(\mathbf{X}(v))$ - the marginal cost of movement of the traffic stream on the analyzed part of the transport network (the marginal cost of movement of the traffic stream on the roads $p$ in relation $(a, b)$ for each variant $v$ are equal and take the minimum value):

$$
f_{2}(\mathbf{X}(v))=\min _{\{\mathbf{X}(v)\}}\left\{m^{p, a b}(\mathbf{X})=m^{p^{\prime}, a b}(\mathbf{X})\right\}
$$

- $f_{3}(\mathbf{X}(v))$ - costs in the form of carbon dioxide emitted by a passenger traveling on the analyzed part of transport network (the total amount of carbon dioxide emitted by passengers traveling on the roads $p$ in relation $(a, b)$ for each variant $v$ are equal and take the minimum value:

$$
f_{3}(\mathbf{X}(v))=\min _{\{\mathbf{X}(v)\}}\left\{e^{p, a b}(\mathbf{X})=e^{p^{\prime}, a b}(\mathbf{X})\right\}
$$

Based on this partial criterion the impact of carbon emissions on the traffic stream distribution will be estimated.

The global criterion function $F(\mathbf{X}(v))$ consists of the three sub-criteria according to variants $\mathbf{X}(v)$ that are estimated for the distribution of the traffic stream on the analyzed part of the transport network. This network states communication corridor Warsaw - Krakow. It is, therefore a vector defined as follows: 


$$
F(\mathbf{X}(v))=\left\langle f_{1}(\mathbf{X}(v)), f_{2}(\mathbf{X}(v)), f_{3}(\mathbf{X}(v))\right\rangle \longrightarrow \min
$$

Every variant of the traffic stream distribution $X(v)$ must comply the restrictions and conditions imposed on the traffic stream $[6,18]$ :

- condition for the implementation of the demand for transport (ZNP):

$$
\forall v \in \boldsymbol{V} \quad \forall(a, b) \in \boldsymbol{E} \quad \sum_{p \in P^{a b}} x^{p, a b}(v)=x^{a b}(v)
$$

- condition for the non-negativity of the traffic stream (NP):

$$
\forall v \in \boldsymbol{V} \quad \forall(i, j) \in \boldsymbol{L} \quad x_{i j}(v) \geq 0
$$

- condition for the additivity of the traffic stream(AP):

$$
\forall v \in \boldsymbol{V} \quad \forall(i, j) \in \boldsymbol{L} \quad \sum_{(a, b) \in E} \sum_{p \in P^{a b}} x_{i j}^{p, a b}(v)=x_{i j}(v)
$$

- condition for sustaining of the traffic stream (ZP):

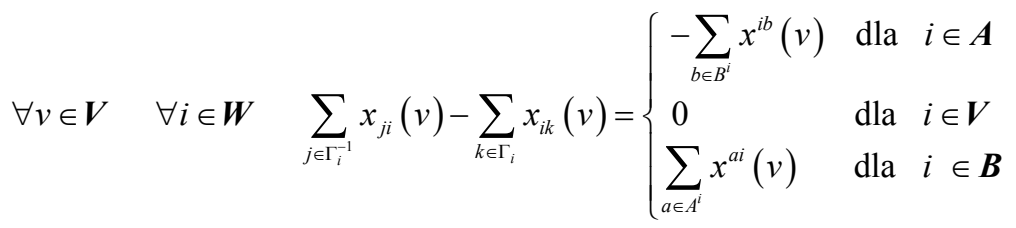

- condition regarding the capacity of the network arcs:

$$
\forall v \in \boldsymbol{V} \quad \forall(i, j) \in \boldsymbol{L} \quad \sum_{(a, b) \in E} \sum_{p \in P^{a b}} x_{i j}^{p, a b}(v) \leq d_{i j}
$$

where: $d_{i j}$ - capacity of the $(i, j)$ connection.

\section{Distribution of a traffic stream on the network}

For the purpose of modeling of traffic stream distribution the following elements of $\boldsymbol{W}$ and $\boldsymbol{L}$ sets were defined:

$$
\begin{gathered}
\boldsymbol{W}=\{1,2,3,4,5,6,7,8,9,10,11,12\} \\
\boldsymbol{L}=\left\{\begin{array}{l}
(1,2),(1,3),(1,4),(1,5),(1,11),(2,6),(3,7),(4,8), \\
(5,9),(6,10),(7,10),(8,10),(9,10),(11,12),(12,10)
\end{array}\right\}
\end{gathered}
$$


Arc $(2,6)$ have an interpretation of rail connection between Warsaw and Cracow by Central Railway Main Line (Centralna Magistrala Kolejowa). Arc (3,7) showing an existing air connection between Warsaw Okęcie Airport and Cracow Balice Airport. Arc $(4,8)$ is a road connection between center of Warsaw and Cracow center. Arc $(5,9)$ is a bus connection between Warsaw, west station and regional bus station in Krakow. Main element of arcs representing a road transport is a national road No. 7. Additionally, in the third variant arc $(11,12)$ will be considered. It is include planned to build a connection of High Speed Rail, which in part will be done as part of the No. 4 line (Central Railway Main Line), followed by Bukowno, Olkusz and Cracow Balice Airport.

Traffic stream distribution was made using the Solver. The distribution was made for variants defined in Section 3.

Tables 1 and 2 shows load of the strategic arc in the transport network for the first and the second partial criterion of solution quality assessment.

Table 1: Arc load [thous. pass./year] for the distribution of traffic stream according to the criterion of the equal average costs.

\begin{tabular}{cccccc}
\hline No. & Arc & Interpretation & Variant 1 & Variant 2 & Variant 3 \\
\hline $\mathbf{1}$ & $\mathbf{2}$ & $\mathbf{3}$ & $\mathbf{4}$ & $\mathbf{5}$ & $\mathbf{6}$ \\
$\mathbf{1}$ & $(2,6)$ & Rail connection & 599,669 & 714,404 & 675,187 \\
$\mathbf{2}$ & $(3,7)$ & Plane connection & 28,146 & 175,662 & 125,240 \\
$\mathbf{3}$ & $(4,8)$ & Car connection & 263,364 & 357,240 & 325,153 \\
$\mathbf{4}$ & $(9,10)$ & Bus connection & 308,820 & 402,694 & 370,608 \\
$\mathbf{5}$ & $(11,12)$ & HSR connection &.$--\ldots$ &.$--\ldots$ & 153,812 \\
\hline
\end{tabular}

Table 2: Arc load [thous. pass./year] for the distribution of traffic stream according to the criterion of the equal marginal costs.

\begin{tabular}{cccccc}
\hline No. & Arc & Interpretation & Variant 1 & Variant 2 & Variant 3 \\
\hline $\mathbf{1}$ & $\mathbf{2}$ & $\mathbf{3}$ & $\mathbf{4}$ & $\mathbf{5}$ & $\mathbf{6}$ \\
$\mathbf{1}$ & $(2,6)$ & Rail connection & 452,815 & 567,550 & 513,466 \\
$\mathbf{2}$ & $(3,7)$ & Plane connection & 210,760 & 358,278 & 288,743 \\
$\mathbf{3}$ & $(4,8)$ & Car connection & 256,848 & 350,722 & 215,564 \\
$\mathbf{4}$ & $(9,10)$ & Bus connection & 279,576 & 373,450 & 329,200 \\
$\mathbf{5}$ & $(11,12)$ & HSR connection &.---- &.---- & 303,028 \\
\hline
\end{tabular}

The arc load for the distribution of traffic stream according to the criterion of equal average costs are shown in figure 1, and the criterion of equal marginal cost in figure 2. The Y-axis shows the size of the traffic stream in thousands of passengers per year. The bars on the graph represent values of the traffic stream sequentially for first, second and third variant. 


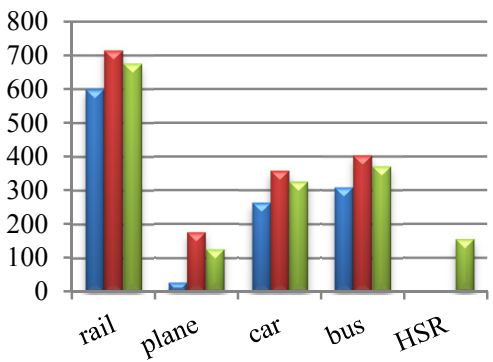

Figure 1: The traffic stream chart distribution according to equal average costs.

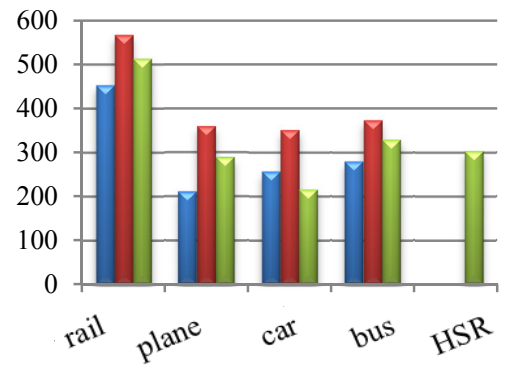

Figure 2: The traffic stream chart distribution according to equal marginal costs.

Table 3 shows the arc load in the strategic transport network for the third criterion - distribution according to the criterion of the total carbon dioxide emissions from passenger for all the analyzed variants.

Table 3: Arc load [thous. pass./year] for the distribution of traffic stream according to the criterion of the carbon dioxide emission.

\begin{tabular}{cccccc}
\hline No. & Arc & Interpretation & Variant 1 & Variant 2 & Variant 3 \\
\hline $\mathbf{1}$ & $\mathbf{2}$ & $\mathbf{3}$ & $\mathbf{4}$ & $\mathbf{5}$ & $\mathbf{6}$ \\
$\mathbf{1}$ & $(2,6)$ & Rail connection & 470,244 & 646,585 & 473,925 \\
$\mathbf{2}$ & $(3,7)$ & Plan connection & 133,908 & 184,123 & 134,956 \\
$\mathbf{3}$ & $(4,8)$ & Car connection & 150,056 & 206,328 & 140,551 \\
$\mathbf{4}$ & $(9,10)$ & Bus connection & 445,792 & 612,964 & 449,282 \\
$\mathbf{5}$ & $(11,12)$ & HSR connection &.---- & $-\ldots--$ & 451,286 \\
\hline
\end{tabular}

Above values are shown in figure 3.

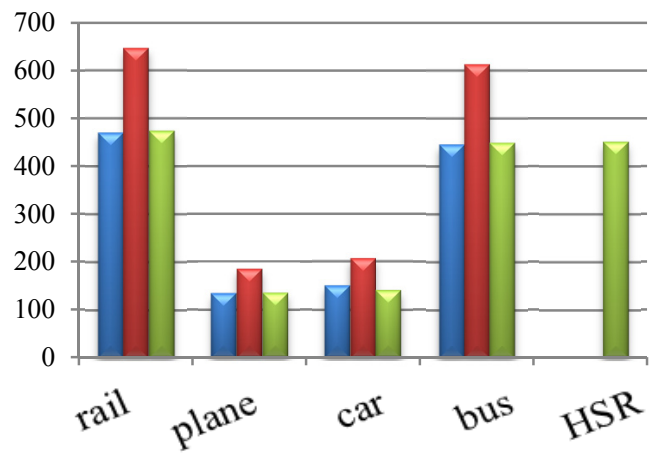

Figure 3: Chart of passenger stream load for connections in different variants. 


\section{Distribution of the traffic stream on network}

Section 5 presents distribution of the passenger stream in part of the transportation network which is communication route Warsaw-Krakow. Each variant is characterized by the corresponding value of objective function. Next will be carried out multi-criteria evaluation of individual variants. It will allow to selecting the best option. To do that, multi-criteria evaluation method, called Maja, will be used [9].

\section{A. Matrix of evaluations of traffic stream distribution variants}

Evaluation of each variant was carried out due to the previously highlighted sub-criteria, interpreted as average costs $\left(f_{1}(\mathbf{X}(v))\right)$, marginal costs $\left(f_{2}(\mathbf{X}(v))\right)$, and cost of amount of $\mathrm{CO}_{2}$ emitted by passenger $\left(f_{3}(\mathbf{X}(v))\right)$. Due to the fact, that all variants were evaluated on the basis of various sub-criteria it should be carried out normalization of evaluations (the value of the objective function was expressed in various units).

Matrix of evaluations of traffic stream distribution variants is as follows:

\begin{tabular}{c|ccc|ccc} 
& \multicolumn{3}{|c|}{ Before normalization } & \multicolumn{3}{c}{ After normalization } \\
\cline { 2 - 7 } & $f_{1}(\mathbf{X}(v))$ & $f_{2}(\mathbf{X}(v))$ & $f_{3}(\mathbf{X}(v))$ & $f_{1}(\mathbf{X}(v))$ & $f_{2}(\mathbf{X}(v))$ & $f_{3}(\mathbf{X}(v))$ \\
\hline Variant 1 $(\mathbf{X}(1))$ & 148,9702 & 176,5066 & 703,0144 & 1,00 & 1,00 & 1,00 \\
Variant 2 $(\mathbf{X}(2))$ & 159,2964 & 197,1589 & 966,6448 & 0,94 & 0,90 & 0,73 \\
Variant 3 $(\mathbf{X}(3))$ & 155,7668 & 187,4239 & 708,5182 & 0,96 & 0,94 & 0,99
\end{tabular}

B. Determination of the relative importance of the criteria

Following relative importance was assumed $c(s), s=1,2,3$ for each sub-criteria: $c(1)=3, c(2)=2, c(3)=5$.

C. Matrix of consistency and inconsistency of variants

Based on normalized matrix of evaluations was prepared matrix of consistency and inconsistency of variants evaluation:

\begin{tabular}{cccc}
\hline \multicolumn{4}{c}{ MATRIX OF CONSISTENCY } \\
\hline Variants & $(\mathbf{X}(1))$ & $(\mathbf{X}(2))$ & $(\mathbf{X}(3))$ \\
$(\mathbf{X}(1))$ & 0 & 1 & 1 \\
$(\mathbf{X}(2))$ & 0 & 0 & 0 \\
$(\mathbf{X}(3))$ & 0 & 1 & 0 \\
\hline
\end{tabular}

\begin{tabular}{cccc}
\hline \multicolumn{4}{c}{ MATRIX OF INCONSISTENCY } \\
\hline Variants & $(\mathbf{X}(1))$ & $(\mathbf{X}(2))$ & $(\mathbf{X}(3))$ \\
$(\mathbf{X}(1))$ & 0 & 0 & 0 \\
$(\mathbf{X}(2))$ & 1 & 0 & 0,97 \\
$(\mathbf{X}(3))$ & 0,22 & 0 & 0 \\
\hline
\end{tabular}

\section{Graph of solutions domination}

In order to build the graph of domination it was assumed bound of consistency $p z=0,7$ and bound of inconsistency $p n=0,3$.

Based on the analysis of solutions it can be drawn the following conclusions:

- the best variant of distribution of the passengers stream is solution defined by node No. 1 - what means variant No. $1-(\mathbf{X}(1))$. It follows that a transportation network is able to handle present volumes of traffic. 
- the worst variant of distribution of the passengers stream is solution defined by node No. 2 - what means variant No. 2 - (X(2)). It means that increasing volumes of traffic in existing structure of transportation network will increase costs and existing transport connections could be too expensive for decision makers.

- indirect variant of distribution of the passengers stream is solution defined by node No. 3 - what means variant No. $3-(\mathbf{X}(3))$. It means that increasing volumes of traffic should be connected with investments in transport infrastructure. So in a future a communication route Warsaw-Krakow should be improved and expanded (e.g. build High Speed Rail). It will result decreasing in costs generated by the transport at the Warsaw-Krakow route.

\section{Conclusion}

The article carried out the distribution of passenger traffic stream on a part of the transport network in the Warsaw-Krakow connection. An important element of the assessment of solutions for individual variants was the criterion of costs associated with the emission of carbon dioxide by passengers who chose a particular type of transport.

Based on the analysis it can be concluded that with the existing structure of the connections in the communication stream, most of traffic should be handled by trains and long distance buses of public transport.

The same conclusion can be drawn in the case of distribution for the second variant (increasing stream of passengers without changing the structure of the diagram). On the other hand, in the case of third variant, which assumes the existence of a line of High Speed Rail traffic stream was almost equally divided between conventional rail and high speed rail. In the next place there were: long-distance public transport buses, cars and airplanes.

Based on these considerations there can be following conclusions: the most environmentally friendly (characterized by the lowest carbon emissions by passenger) are railways.

They should serve the greatest number of passengers. Large share in the passengers transport should have long-distance public transport buses. Cars because of the fact that they usually are used only by one passenger, emit quite a lot of $\mathrm{CO}_{2}$ into the atmosphere.

The largest emission characterize airplanes, which passengers emit most compounds into the atmosphere.

\section{Acknowledgement}

This scientific research was carried out under the project "Proecological transport system designing" (EMITRANSYS) funded by the National Centre for Research and Development. 


\section{References}

[1] Ambroziak T., Gołębiowski P., Pyza D., Jacyna-Gołda I., Żak J.: Identification and Analysis of Parameters for the Areas of the Highest Harmful Exhaust Emissions in the Model EMITRANSYS, w: Journal of KONES, Institute of Aviation, vol. 20, nr 3, 2013, ss. 9-20.

[2] Bauer J. Bektas T., Crainic T.: Minimizing greenhouse gas emission in closed - loop supply chain research. Prod Oper Manag 17: 483-496, 2009.

[3] $\mathrm{CO}_{2}$ Emissions from Fuel Combustion Highlights, International Energy Agency, 2012.

[4] European Environment Agency: EMEP/EEA air pollutant emission inventory guidebook [on-line]. [dostęp 30 marca 2013]. Dostępny w World Wide Web: http://www.eea.europa.eu/publications/emep-eea-emissioninventory-guidebook-2009.

[5] Hoen K., Tan T., Fransoo J., Houtum G., Effect of carbon emission regulations on transport mode selection under stochastic demand, Flex Serv manuf J (2014) 26: 170-195.

[6] Jachimowski R., Kłodawski M., Lewczuk K., Szczepański E., Wasiak M: Implementation of the model of proecological transport system, w: Journal of KONES, vol. 20, nr 4, 2013, ss. 129-139.

[7] Jacyna M., Szczepański E.: Holistic approach to the ecological cargo distribution in urban areas with the use of multi-modal transport, w: WIT Transactions on The Built Environment, WIT Press, vol. 130, 2013, ss. 53-65, DOI: 10.2495/UT130051.

[8] Jacyna M., Żak J., Jacyna-Gołda I., Merkisz J., Merkisz-Guranowska A., Pielecha J.: Selected aspects of the model of proecological transport system, w: Journal of KONES, Institute of Aviation, vol. 20, nr 4, 2013, ss. 193-202.

[9] Jacyna M.: Multicriteria Evaluation of Traffic Stream Distribution in a Multimodal Transport Corridor, Taking into Account Logistics Base Service. Archives of Transport, Polish Academy of Sciences, Com. of Transport, vol. 10, iss. 1-2, Warsaw, 1999.

[10] Jacyna M.: Multicriteria Evaluation of Traffic Stream Distribution in a Transport Corridor. Railway Engineering, London 30.04-1.05. 2001.

[11] Lewczuk K., Żak J., Pyza D., Jacyna-Gołda I.: Vehicle routing in urban area - environmental and technological determinants, w: WIT Transactions on the Built Environment, WIT Press, vol. 130, 2013, ss. 373-384, DOI:10.2495/UT130291.

[12] Mensink C, De Vlieger I, Nys J.: An urban transport emission model for the Antwerp area. Atmospheric Environment . Elsevier. Volume 34. Issue 27/2000.

[13] Merkisz J., Merkisz-Guranowska A., Pielecha J., Fuc P., Jacyna M.: On-road Exhaust Emissions of Passenger Cars using Portable Emission Measurement System (PEMS), w: Conference Proceedings Architecture and Civil Engineering, Global Science and Technology, 2013, DOI:10.5176/2301-394X_ACE13.71\#sthash.11jyQJwD.dpuf. 
[14] Merkisz J., Merkisz-Guranowska A., Pielecha J., Nowak M., Jacyna M., Lewczuk K., Żak J.: Exhaust emission measurements in the development of sustainable road transport, w: Journal of KONES, vol. 20, $\mathrm{nr} 4$, 2013, ss. $277-284$.

[15] Merkisz J., Pielecha J., Radzimirski S.: New Trends in Emission Control in the European Union Springer Tracts on Transportation and Traffic, Vol. 4, 2014, p. 170.

[16] Merkisz-Guranowska A., Merkisz J., Kozak M., Jacyna M.: Development of a sustainable road transport system, w: WIT Transactions on The Built Environment, WIT Press, vol. 130, 2013, ss. 507-517, DOI: 10.2495/UT130411.

[17] Trends in Global $\mathrm{CO}_{2}$ Emissions, 2013 Report, PBL Netherlands Environmental Assessment Agency.

[18] Zeleny M.: Multiple criteria decision making. MCGraw-Hill, New York, 1982. 